\title{
An Exploratory Study of Older Adults' Social Media Use and Social Capital in Nigeria
}

\author{
By Rodney Ciboh*
}

\begin{abstract}
This study focuses on the benefits of social network sites especially in terms of what older adults derive from their social relationships and interactions on these sites. Drawing on a sample of 336 older adults, ages 50 years and older working in 13 government ministries in Benue State, Nigeria, results show that Nigerians go online regularly using mostly their mobile phones and spend much of their time on social media platforms, on Facebook predominantly. These results suggest that some older Nigerian adults are relatively "heavy" social media users and social networking has become a daily part of life. But the benefits that older Nigerians derive from social relationships especially in terms of bonding and bridging social capital are doubtful. The study concludes that although older adults' interactions on SNS are seemingly constitutive of bonding and bridging the social capital but these are not predictive of substantive forms of capital exchanges typically associated with these forms of social capital such as helping others to solve problems including financial problems, sharing intimate personal problems or gains in form of useful information, personal relationships, or the capacity to align with groups and broaden world-views. Nonetheless, the internet and social media allow older Nigerians the opportunity to create and maintain larger, diffuse networks of relationships and also provide them with a range of benefits and opportunities to empower themselves in a variety of ways.
\end{abstract}

Keywords: bonding, bridging, older adults Nigerians, social networking sites, social capital

\section{Introduction}

Social network sites as one of the most popular Internet services in the world have not only altered the lives of individuals in many ways but have noticeably increased in popularity especially among adolescents and young adults all over the world (Pempek, Yermolayeva, \& Calvert, 2009). Although older adults appear to be late adopters of digital technology compared to younger adults Smith (2014) believes that they are now among the fastest growing users of social media such as Facebook, Twitter, Skype, and LinkedIn, etc. and Lovett (2011) is optimistic that the number of older SNS users is expected to grow significantly in the next years. Older users are now fast embracing social network platforms to help maintain contact with friends, families and colleagues, and manage their daily communications like sharing links, photos, videos, news and status updates (Bell et al., 2013).

Because of the increase in older adults' participation in social networking sites, Baugess (2015) suggests that older adults may greatly be benefitting from social networking activity and it is possible that online social networking plays a positive role in their lives. Indeed, Zhang and Kaufman (2015) say SNS use facilitates intergenerational communication for older adults and appear increasingly beneficial also as common modes of developing new social networks for the older citizens. Wagner, Hassanein and Head (2010) also cite seeking social

\footnotetext{
* Associate Professor, Department of Mass Communication, Benue State University, Nigeria.
} 
support online in coping with grief and dealing with geographic boundaries or limited mobility as some of the other substantial evidence of the benefits of SNS. Other studies on the impact of computer usage for older people suggest that increased social interaction of older people in online environments has a positive correlation with their perceived quality of life and well-being (Xie, 2007) as older people receive, give or exchange information and news and offer emotional support to others.

Since the main purpose of SNS is communication, Shklovski, Kraut and Rainie (2004) argues, it is only logical to expect that SNS use will have a positive impact, both in terms of its users' social integration in a network of family, friends, and community and the benefits that flow from this integration. Hence older adults use the resources available on social network of personal contacts to achieve personal goals suggest the benefits of SNS to build and maintain the social capital. However, they mostly focus on the population of college students. So far there is little research on how older people use and adopt these new arenas for social interaction in general and social capital in particular.

In an earlier study of older adults' social network site use in Nigeria and what implications and gains they derive from their activities on these sites, Ciboh (2015) found that overall, older Nigerian adults' communication interactions on SNS not only appeared inclined to building and maintaining social relationships that are constitutive of bonding social capital but also seemed to augment bridging social capital from which they could possibly draw resources. Hence this further research into the social capital implications of such interactions for the older generation. Thus this exploratory research paper addresses this gap by examining: the motivations underpinning $50+$ yearolds' uptake of SNS, the types of relationships they form and maintain through using the site; and the social capital benefits accrued through their use. How then do older people use SNS to build and maintain social capital in Nigeria?

\section{Literature Review}

The concept of social capital is associated with group membership and social networks or social connections and the benefits that may arise from these connections for groups and individuals. Thus research on social capital is organized around two themes - one that emphasizes the benefits of social capital for individuals and one that emphasizes its group benefits. Individuals may access social capital resources such as useful information, personal relationships, opportunities for professional development (Phulari et al., 2010) and social, emotional and practical support (Gray, 2009). On a community level, social capital may foster social cohesion through "the norms of reciprocity and trustworthiness" that flow from social networks (Putnam, 2000, p. 19).

Social capital at an individual level is generally referred to as a bonding social capital and is derived from intimate ties of trust and cooperation found in tightly-knit, emotionally close relationships or within homogeneous groups such as family and close friends (Steinfield, Ellison, \& Lampe, 2008, p. 436) or 
in people who are like in important respects or similar social identity such as age, ethnicity, class, family (Szreter \& Woolcock, 2004). Putnam (2000) characterises bonding social capital as exclusive, occurring among close connections that may be beneficial for the accessibility of rare resources and emotional and substantive support. Bonding social capital is most commonly associated with psychological well-being, such as self-esteem and satisfaction with life (Bargh, McKenna, \& Fitzsimons, 2002; Helliwell \& Putnam, 2004).

On the other hand, "bridging" social capital refers to weak ties among individuals characterised by loose connections better suited for obtaining information or knowledge across social or geographical distances (Norris, 2002). Putnam (2000) sees social capital as a community asset suggesting that "bridging" social capital is inclusive and outward-looking and "better for linkage to external assets and for information diffusion" (p. 22), and may broaden social horizons or world views. Bridging social capital thus is a collective level phenomenon emanating from exposure to a heterogeneous network of largely weak ties or connections such the ones as found among co-workers, classmates, and acquaintances or members of a community or religious organisation (Ellison, Lampe, \& Steinfield, 2009; Putnam, 2000) which link individuals to more resources and facilitate their involvement and active participation in civic, political activities and interest in public affairs. Bridging social capital provides access to non-redundant information, resulting in benefits such as employment connections (Granovetter, 1983).

Another form of social capital is linking social capital which describes the capacity to leverage resources, ideas and information from networks of vertical relationships among individuals, groups and formal institutions beyond the community who differ in power, social status, wealth and influence and who do not necessarily share a collective identity (Poortinga, 2012; Knobel, \& Lankshear, 2008; Woolcock 2001). Linking social capital connects "people in power, whether they are in politically, socially or financially influential positions" (Woolcock \& Sweetser, 2002, p. 26) who have "different amounts of power and resources, and different interests" vertically to "higher levels of decision-making and resource allocation" "government, business, and civic organizations" (World Bank, 1997, p. 110). Linking social capital is supposedly best able to provide instrumental support in community and society development.

Many studies recognise the benefits of social capital associated with social network sites. Several of the studies investigating the relationship between social network sites and social capital (Ellison, Steinfield, \& Lampe, 2007; Lampe, Ellison, \& Steinfield, 2006; Steinfield, Ellison, \& Lampe, 2008) consistently conclude that social network sites correlate strongly with social capital and can contribute to the formation and maintenance of all forms of social capital among the population of especially young adults and college or University-aged students. Social network sites support the users' ability to form and maintain a wide network of social connections and add to the formation and maintenance of all forms of social capital. Ellison, Steinfield and Lampe (2011) confirm that social capital expresses the benefits individuals derive from their social relationships and interactions: resources such as emotional support, exposure to diverse ideas, and 
access to non-redundant information. Papacharissi and Mendelson (2008) for instance, found that using Facebook to share the public and private information medium to relax in an entertaining manner also lends "those mobile and leading a socially activity are able to reap the social benefits and employ same to increase bonding and bridging social capital" (p. 22). Burke, Marlow and Lento (2010) also found that Facebook overall use was strongly associated with social capital especially bonding social capital.

Many other studies as well recognise potentials of social networking sites to generate and maintain social capital for older adults. Most common benefits of social networking sites for older adults are indentified as a relief of depression (Cotten, Ford, Ford, \& Hale, 2012; Gibson et al., 2010), relief of stress (Hogeboom, McDermott, Perrin, Osman, \& Bell-Ellison, 2010), and as generally improving life-satisfaction through increased social support (Pfeil, 2007; Sundar, Oeldorf-Hirsch, Nussbaum, \& Behr, 2011). At least three main types of social support can be distinguished: emotional (providing intimacy, attachment, caring, and concern); informational (providing advice, guidance, or information relevant to the situation); and instrumental (providing aid or assistance) (House \& Kahn, 1985; House, Umberson, \& Landis, 1988).

Essentially, the main benefit of using social networking sites for older adults, according to Nef, Ganea, Müri and Mosimann (2013) is to enter in an intergenerational communication with younger family members (children and grandchildren). Hence, Nef et al. (2013) say using social networking sites might be a good means of communication to help keep up with what is going on in the lives of family members who are active on SNS. At the same time, Farkas (2010) too believes that social networking sites can be a way to reduce social isolation, loneliness, and promote involvement of older people in their family life. Particularly for senior citizens with limited mobility, Erickson (2011) observes, SNS may help them maintain and underpin existing contacts and connections (Erickson, 2011). Additionally, older people are found to enjoy a sense of community living online where they exchange all levels of supportive communication (Wright, 2000; Pfeil and Zaphiris, 2007).

More studies are investigating social networking sites use and social capital or how SNS improve quality of life for older adults but the growing body of literature are being generated in the USA and other Anglophone settings. Relatively, only few studies have attempted to investigate SNSs usage and social capital especially among older Nigerians. This study thus attempts to fill this gap by focusing on the following research questions:

RQ1: What is the frequency of older adults' use of social network sites?

RQ2: Which is their most preferred social network site?

RQ3: What kinds of social relationships do they form and maintain on these sites?

RQ4: What benefits do they derive from these social relationships and interactions? 


\section{Methodology}

Although there are several methods for measuring social capital in online social networks, this study adopts Williams' (2006) framework - the Internet Social Capital Scales (ISCS) of measuring "social capital" which has been used in some of the most highly cited studies on SNS and social capital. Williams (2006) acknowledged the bridging and bonding dimensions of social capital and developed the ISCS to measure outcomes attributed to social capital. His bonding and bridging subscales consisted of 10 items, each on a 5-point Likert scale for a total of 20 questions. In this research, we combine frequency of use and time on site with his Likert-scale attitudinal items based on self-reports. Appel et al. (2014) say of the published papers utilizing the ISCS, fewer than $10 \%$ use the original ISCS as proposed by Williams (2006). Rather, they say, the majority of papers are based on revised versions of the ISCS. We here also utilise the 5-point Initiating Likert Scale items reported in Ellison, Steinfield and Lampe (2011) for kinds of social relationships older adults form on SNS and the Williams' (2006) Internet Social Capital Scales (Appel et al., 2014, p. 401) to establish the outcomes or benefits older adults derive from their social relationships and interactions on these sites.

For ISCS, we sought to be more specific and removed the "offline" dichotomy in both the bonding and bridging subscales. Then we substituted "friends, relations, neighbours, colleagues" and "strangers" for the more general reference to "people" in the bonding and bridging subscales respectively. For these variations, we are guided by the arguments which suggest that online and offline life are not clear dichotomies but rather a single, social system that is part of everyday life (Rainie \& Wellman, 2012; Wellman \& Hampton, 1999) albeit, we accept that a scale that has been modified in its wording or adjusted by increasing or decreasing the number of scale items might not have the same psychometric qualities as the original or even measure the same phenomena (Furr, 2011).

To characterize "older people" on social network sites, we acknowledge the difficulty in defining "old" especially that age classification varies among countries and over time (Seeman, Lusignolo, Albert, \& Berkman, 2001). Thus, in this study, we accept the age limits suggested by the World Health Organisation (WHO, 2014) which puts Nigeria's life expectancy at 56 years (female 56 years, male 53 years). This puts the average of an "older Nigerian" at about 55 years. Thus any civil servant between the ages of 50+ was considered in this study as a senior citizen.

To examine the relationship between older adults' experiences with SNSs and their social capital, we conducted a survey in 13 government ministries and departments in the Makurdi Benue State, Central Nigeria during the months of February and March of 2016. A total of 400 civil servants were randomly sampled using convenience sampling to eliminate the difficulty involved in surveying the population (Saunders, Lewis, \& Thornhill, 2012) evenly. The research instrument used was a survey questionnaire which made extensive use of five-point Likert scales. The reason for this choice was based on the success achieved from 
previous, similar studies conducted by Ellison et al. (2007) and Johnston, Chen and Hauman (2013).

Only those civil servants who could be reached or those who were close at hand and easily accessible were sampled for the study since the main objective of the study was to obtain preliminary information about SNS use among senior citizens. The questionnaire was administered face-to-face. Researchers met the civil servants directly, introduced themselves, asked them to complete the questionnaire and remained with them to clarify the aspects of the questionnaire some do not understand. The questionnaire was in English, the official language of bureaucracy and administration in Nigeria. Descriptive statistics and corresponding graphics were generated and used for answering all questions and for the interpretation of results for all variables. Then Pearson correlations were used to test the correlations between the frequency of visits and times spent on the social networking sites and between relationships on social networking sites and potential benefits from such social relationships.

\section{Findings}

Among the 400 of older adults reached with the questionnaire, a total of 336 respondents completed them, yielding a response rate of $84 \%$. Thus, final valid sample is $\mathrm{N}=336$.

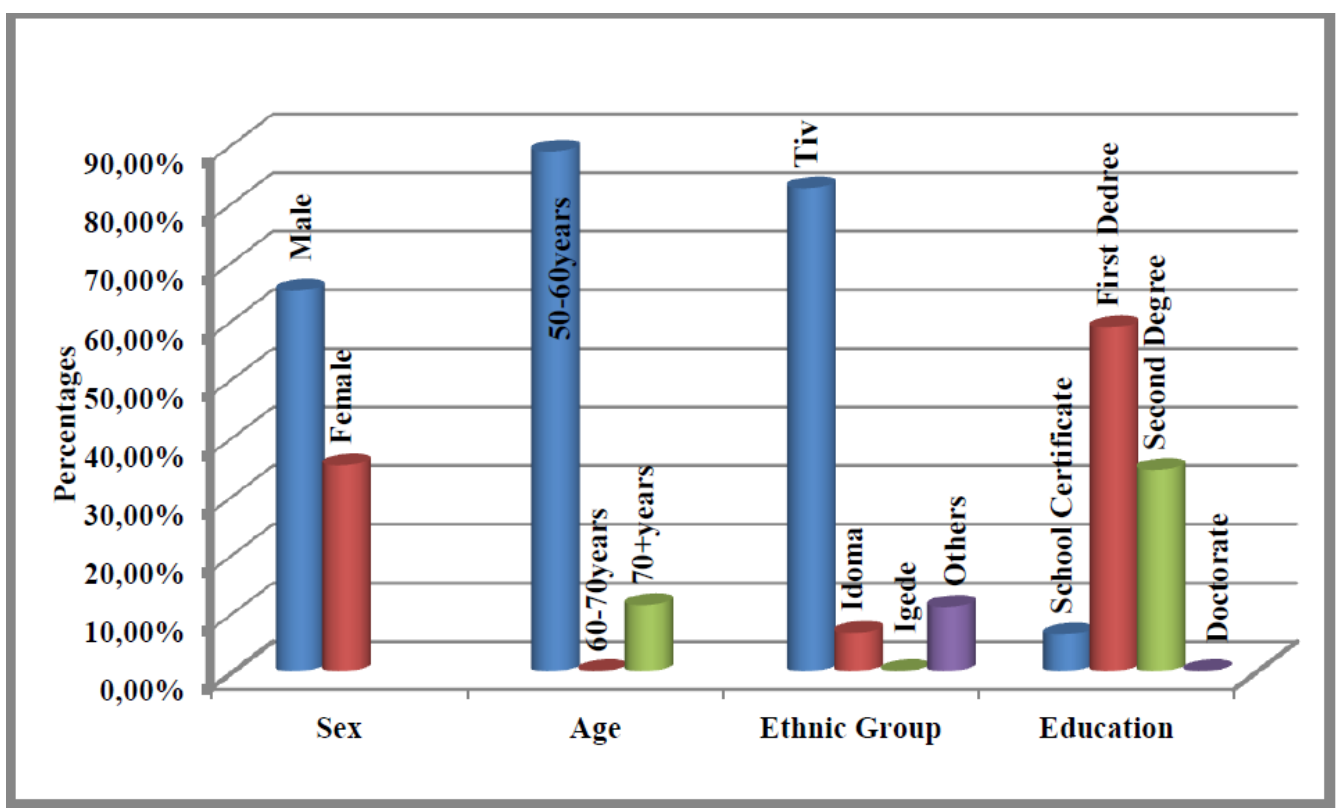

Figure 1. Demographic of Sampled Civil Servants

Frequencies of demographics of senior civil servants in Figure 1 shows that almost twice as many males $(64.88 \%)$ sampled as were females $(35.12 \%)$. The average age for the majority of senior civil servants $(88.69 \%)$ sampled was about 50 years and above with just about one-tenth $(11.01 \%)$ of them putting their age above 70 years. The majority of senior civil servants sampled were 
primarily of Tiv nationality $(82 \%)$, easily the dominant ethnic group in the state. The remaining sample contained almost twice as many other ethnic groups $(11.01 \%)$ as were Idoma $(6.55 \%)$ who are next dominant ethnic group in the state. It is unexpected that none of the civil servants sampled were from the Igede ethnic group considered next to the Idoma in the state. More than half of all senior civil servants $(58.63 \%)$ sampled were highly educated up to the first degree with slightly more than one-third (34.38\%) attaining post-graduate education though none has a doctorate degree.

Figures 2 is concerned with questions related to senior citizens' SNS usage and practices on social networking sites including how often they visit such sites in a week and the average time they spend on such visits.

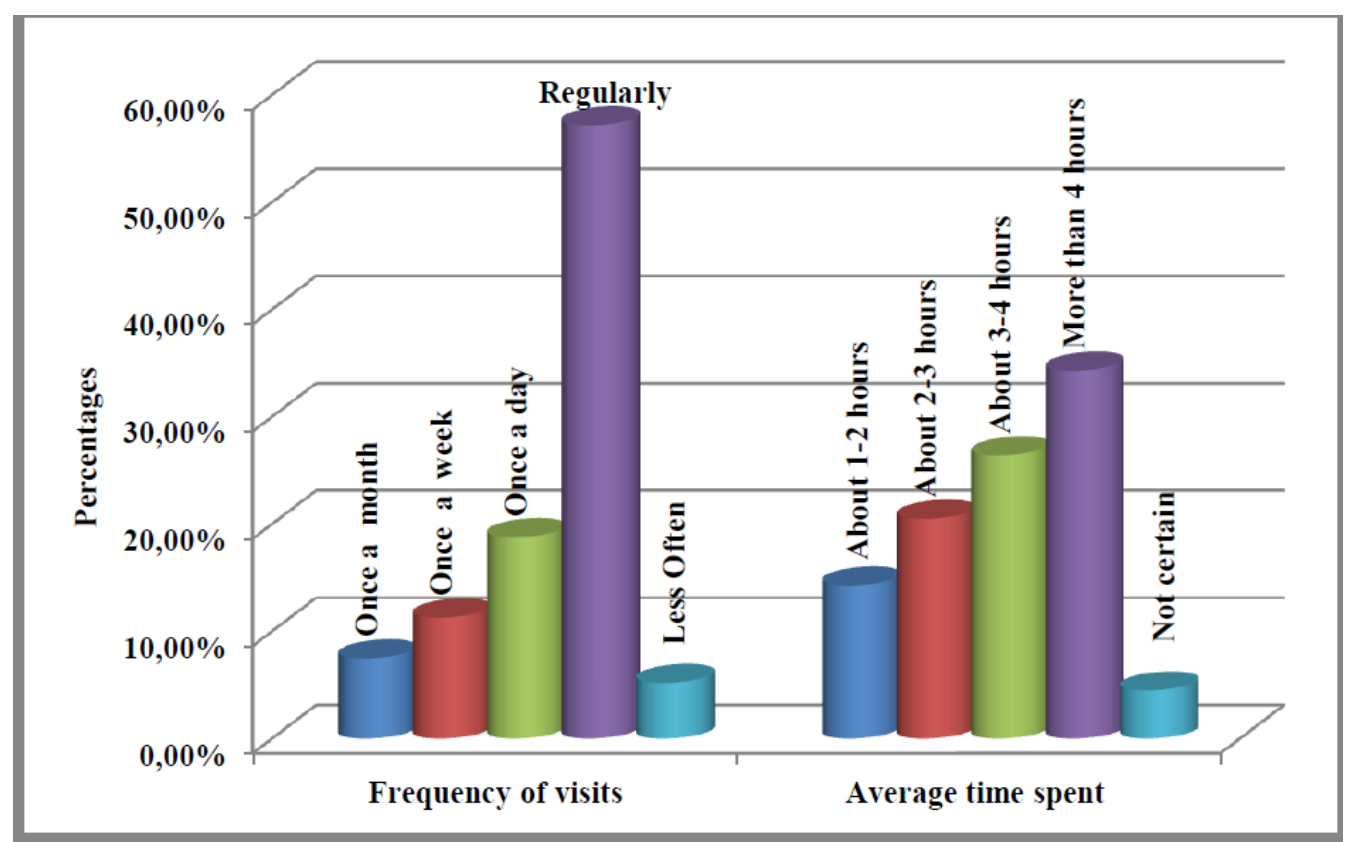

Figure 2. Frequency of Visits and Time of Use

Results show that about one in every seven (14.3\%) of all older people sampled spend at least one to two hours on visits to favourite social network sites. And while about one in every five (20.5\%) of senior citizens say they spend an average of least 2 to 3 hours at any given time, slightly more than one quarter (26.4\%) of all adults sampled say they spend between 3-4 hours whenever online. At least one adult user in about a quarter (4.5\%) of all older civil servants sampled may not be certain what time they spend online but for the majority of more than one-third (34.3\%), visits to their favourite social network sites almost constantly or regularly and may last four hours and more on such visits.

On how often they visit such sites, results seem to suggest a close association between the frequency of visits increase and time spent on social network sites. That is, those who say they use the internet multiple times a day or regularly (57.2\%) admit spending most time (four hours and more) on their favourite social network sites. Conversely, those who log on less often (5.2\%) tend to have no idea of what time they spend online on an average visit. 
Similarly, those who visit their favourite social network site at almost everyday $(18.8 \%)$ say they spend as many as between 3-4 hours daily while those who go online at least once a week (11.3\%) say they spend an average time of between 2 to 3 hours. Also, those who go online once a month $(7.5 \%)$ say they spend at least one hour on each visit. The overall, results show that the frequency of visits or use is positively related to amount of time spent on the social networking sites. Pearson's product-moment correlation coefficient confirms the strong positive relationships $(r=0.846, \mathrm{p}<0.05)$ between the frequency of visits and times spent on the social networking sites.

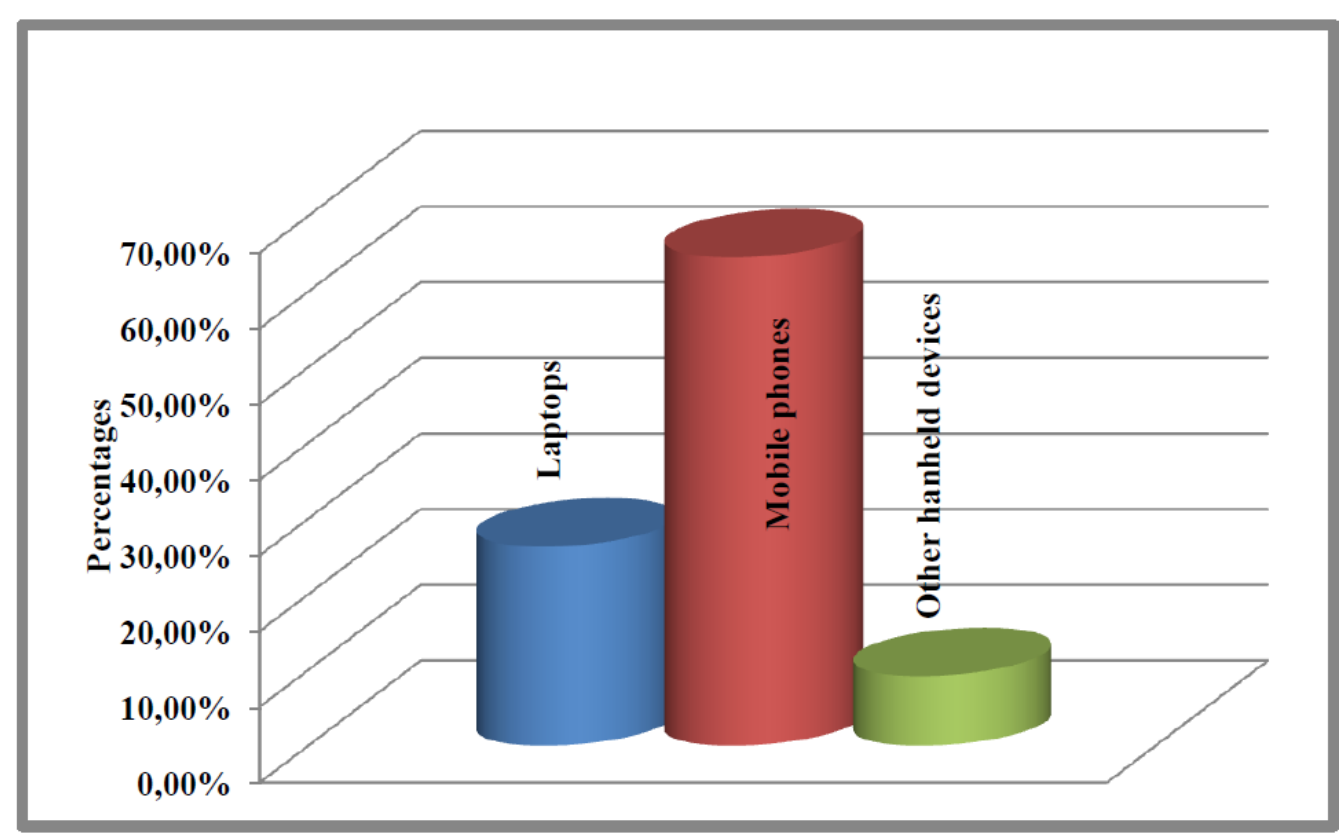

Figure 3. Mode of Access

On questions of how or what devices older citizens use in accessing the internet, Figure 3 above shows most adults sampled use numerous devices to go online. Results indicate that at least one in every four adults $(26.3 \%)$ uses a portable computer, such as a laptop or tablet, to go online. But the most common device for accessing the internet is the mobile phone as more than two - thirds $(64.5 \%)$ of all adults sampled now use their mobile phones of any kind to go online. The use of alternative devices such as music players, e-book readers, gaming devices and other devices only appears ancillary as only about one-tenth $(9.2 \%)$ of adults sampled appear to use them.

In terms of which SNS older adults most favour, data in Figure 4 shows preferences similar results to what obtains among the younger generation. Findings reveal that Facebook is the most popular and widespread social media site among all older Nigerian civil servants studied in the Benue State. Facebook accounts for more than one-third (32.8\%) of all active older adult users sampled. Facebook is followed by Facebook's other services, WhatsApp, which attracts more than one-quarter $(26.7 \%)$ of followers. According to the results, Twitter enjoys patronage of at least one out of every six $(15.5 \%)$ of all 
adults sampled. And while about one in every nine users (10.4\%) patronise Instagram, at least one tenth $(9.1 \%)$ are on LinkedIn every other time. Few of the older civil servants (5.5\%) seem to use other sites like YouTube, Google+, Badoo, 2go, MySpace, Pinterest and others.

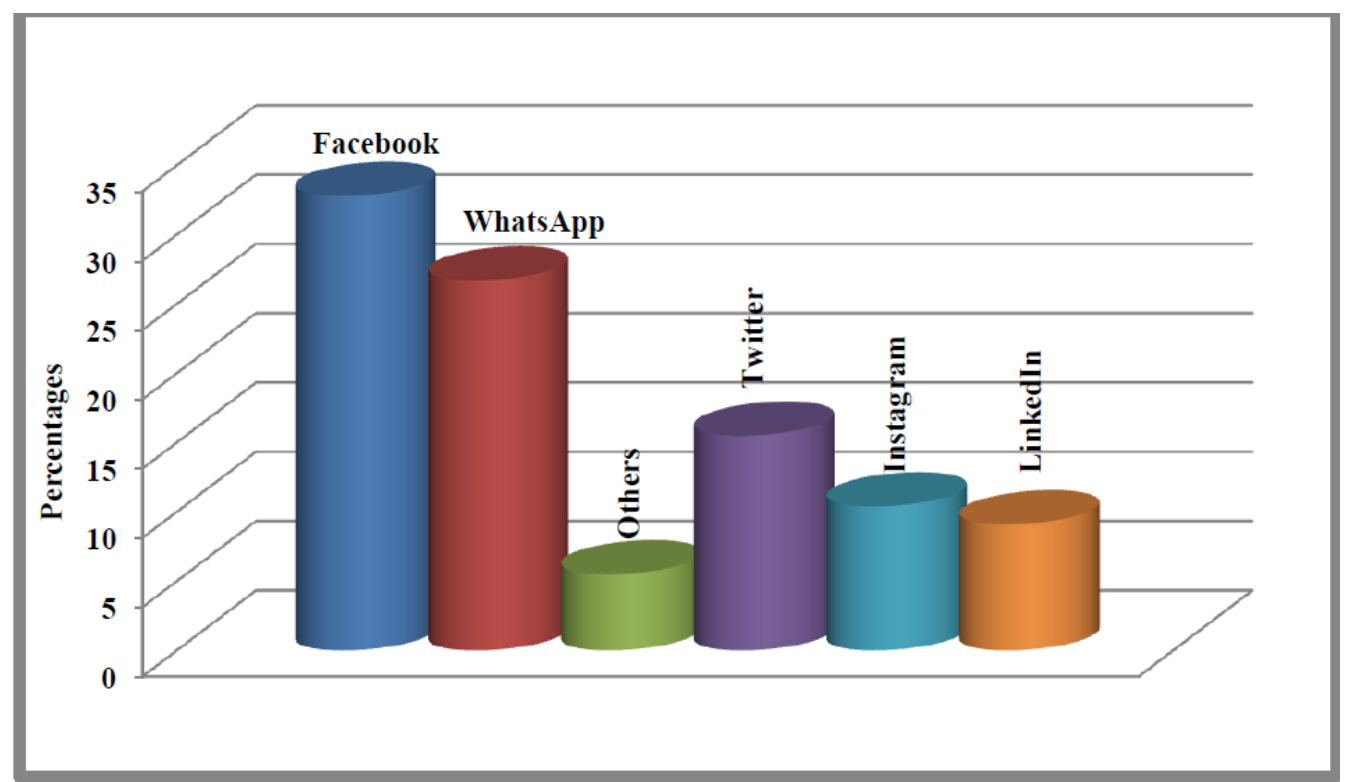

Figure 4. Favourite SNS

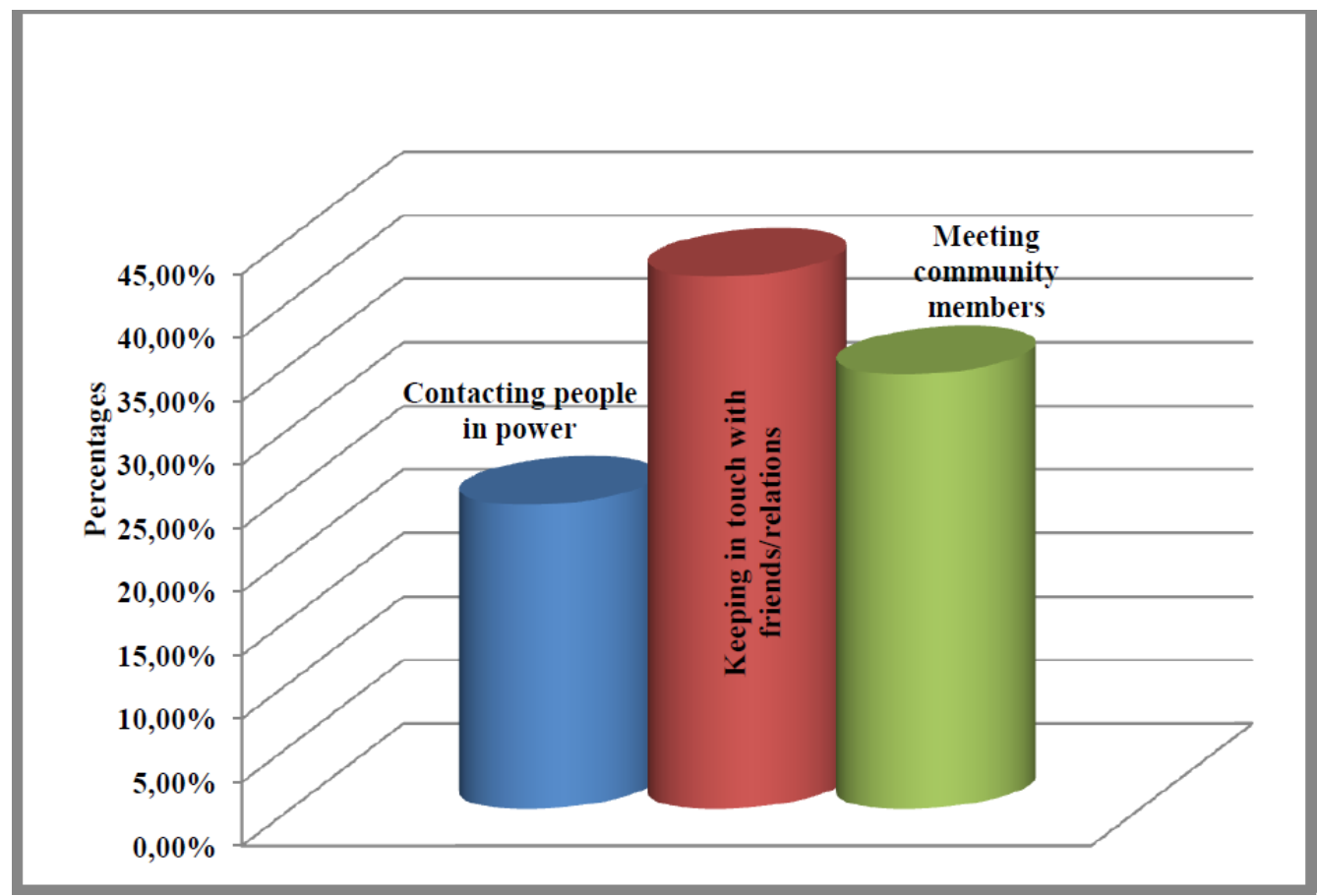

Figure 5. Relationship on SNS

On questions of who older adults regularly contact on social network sites among friends and family members, community members or strangers or those 
in positions of power, results from Figure 5 shows that older adults' $(41.88 \%)$ relationships on social networking sites revolve around communicating with friends and family members. More than half (58.12\%) of all older adults remaining appeared to be outward-looking towards initiating connections, interactions, and the widening circle of social relationships outside friends and relations. Of these, slightly more than one-third (34.19\%) use these sites to meet new people or develop fresh relationships within various communities while about one-quarter $(23.93 \%)$ seek such contacts among those in positions of decision-making and resource allocation whether in government, business or civic organizations.

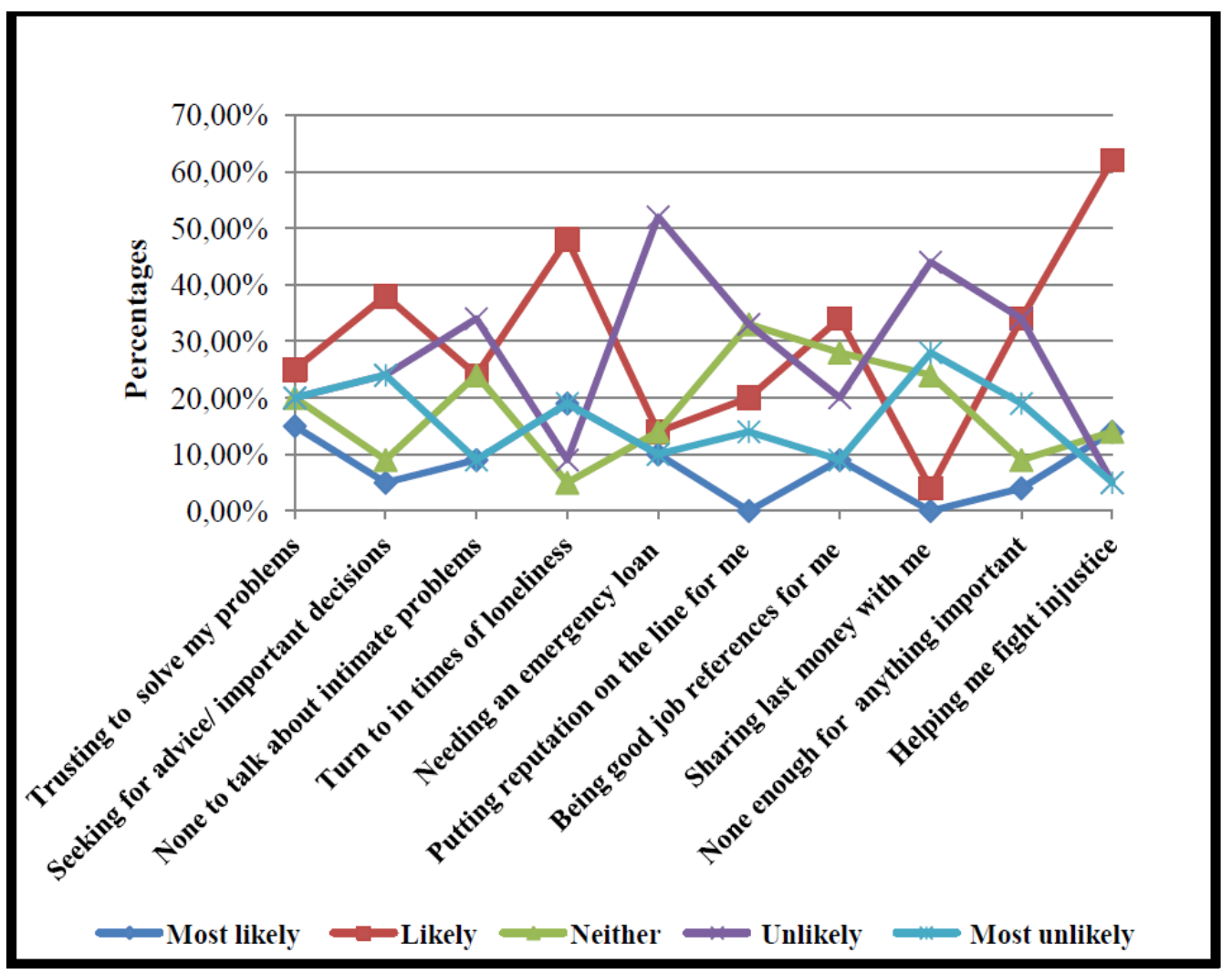

Figure 6. Measures of Bonding Social Capital

Regarding SNS usage and what benefits they derive from social relationships, data from Figure 6 suggests a relatively high likelihood for older adults reaping potential and real benefits of bonding social capital such as accessibility of rare resources and substantive support. The Pearson productmoment correlation coefficient shows positive relationships between using social networking sites and bonding social capital $(r=0.592, \mathrm{p}<0.05)$ though some older civil servants do not seem to trust friends/relations online enough to feel comfortable talking to them about intimate personal problems $(43 \%)$ and none of them seem to think of any friends or relations online they can turn to for financial assistance (62\%) let alone those who are likely to share their last dollar with them (72\%). Results showed most likelihood for potential gains 
especially in emotional support in terms of advice (38\%), helping to fight just causes (62\%), offering companionship in times of loneliness (48\%) and the willingness to serve as job referees as more than a third (34\%) says relations and friends on social networking were good enough job referees. On the flip side, more than one third (34\%) do not seem to know or trust friends or relations online well enough to get them to do anything important for them.

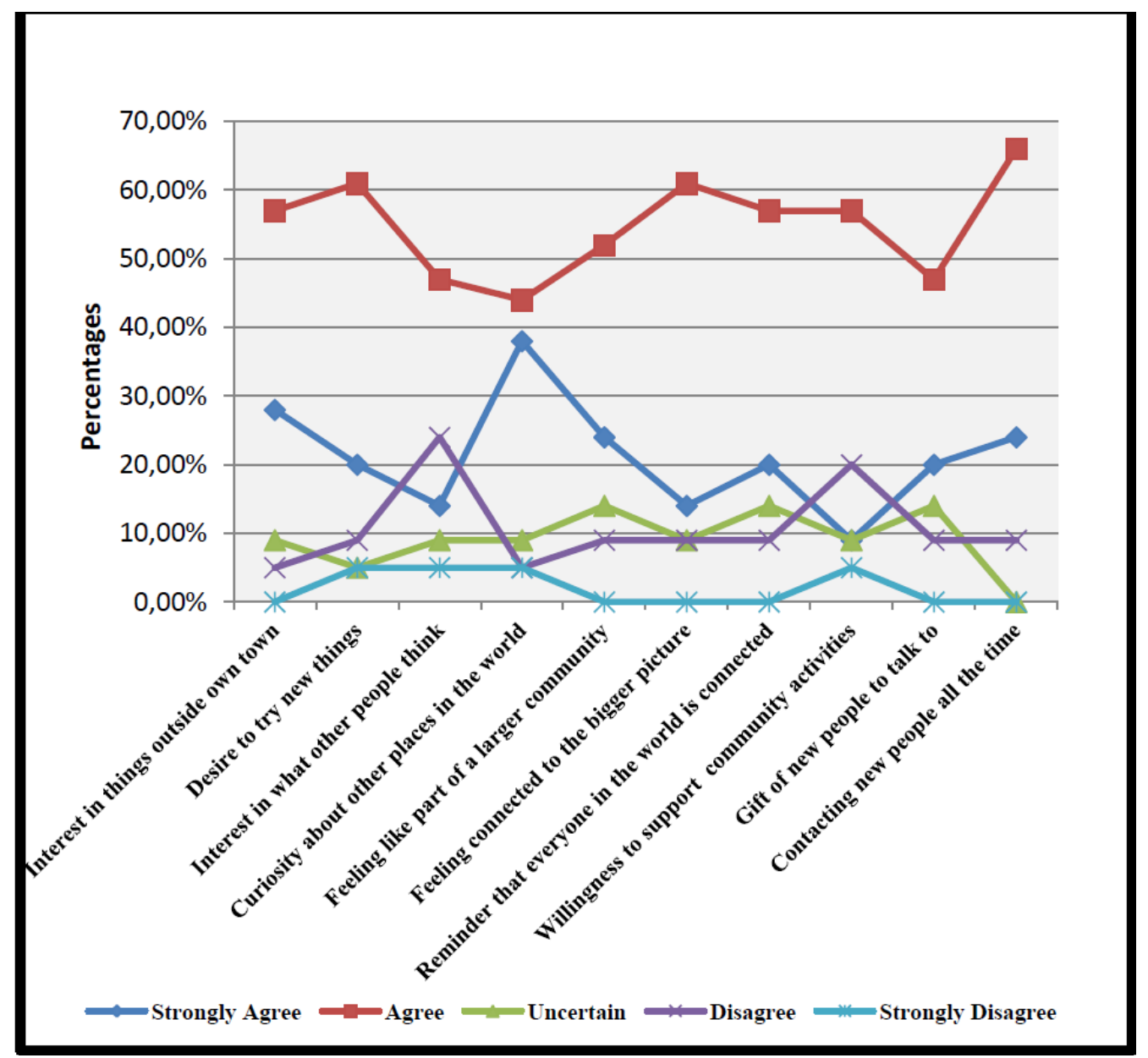

Figure 7. Measures of Bridging Social Capital

Figure 7 measures the social utility of social networking sites for bridging the social capital among older adults. The Pearson product-moment correlation coefficient show results $(r=0.301, \mathrm{p}<0.05)$. This means there is a weak association between the use of SNSs and bridging social capital. Some older civil servants expressed strong feelings of interconnectedness to a larger community and desire to try new things $(61 \%)$ as well as the willingness to develop new ties $(66 \%)$ and are both interested in things outside their home and willing to support their community $(57 \%)$. But this seemingly positive relationship between bridging social capital and the use of SNSs wanes in regard to older adults' curiosity about other places in the world (44\%), their interest in what other people think and the likelihood of older citizens getting new people to talk to (47\%) on social networking sites. 


\section{Discussion}

This study focused on the benefits of social network sites especially in terms of what older adults derive from their social relationships and interactions on these sites. Weighing the correlation between the frequency of exposure and time spent on SNSs $(r=0.846, \mathrm{p}<0.05)$, results suggest that some older adults Nigerians' are relatively "heavy" social media users. This fact is hardly surprising because Nigeria is believed to have the highest number of internet users in Africa up to 97,210,000 Internet users as of June, 2016 representing 52.0\% penetration of the population (Internet World Stats, October 11, 2016). Nigeria is ranked $10^{\text {th }}$ on the list of the world's top internet users and Internet user growth is largely attributed to help of expanded $3 \mathrm{G}$ and $4 \mathrm{G}$ networks, affordable smartphones and advanced feature phones with internet capabilities (eMarketer Report, June 02, 2016). And, according to a Nigerian ICT Solution Provider, Nigerians go online predominantly to spend much of their time on social media platforms (Seal-World, January 24, 2014). For a reasonable number of older adults therefore, social networking has become a daily part of life and Facebook, the major social media platform worldwide, is believed to be the most visited website in most of Nigeria. Facebook has announced that it has an $8.6 \%$ penetration rate and 16 million active users in Nigeria as at June, 2016 (Internet World Stats, October 11, 2016). Because most civil servants sampled reported greater use of social network sites for connecting with existing offline contacts, it means that older adults use social network sites primarily to maintain existing offline relationships. These statistics point to a growing tendency globally toward spending more time online to maintain preexisting social ties and to create new connections (Lin, Peng, Kim, Kim, \& LaRose, 2011). But in recent times, Nigerians are increasingly using social media platforms to demand change from the government and for political participation. The mass protests which attended removal of fuel subsidy by President Goodluck Jonathan in 2012 were organized via Twitter and mobilised beyond social media platforms as well as the bring-back-our-girls campaign in 2014 and the general election that took place in 2015

Results here show that Nigerians go online predominantly with their mobile phones and, according to Ericsson (2013), a world-leading provider of telecommunications equipment and services to mobile and fixed network operators, the mobile phone is slowly becoming the central device in the daily lives of most consumers Sub-Saharan Africa and are among the most owned devices used by Nigerians. Currently, there is a digital divide in access to Information and Communication Technology (ICT) in Sub-Saharan Africa both in terms of adequacy and equality of distribution among the different segments of the population. And Ericsson (2015) says access, use and knowledge of ICT in the region is relatively unique for every individual, household, business and geographical area. The civil servants sampled for this study, constitute the middle class in Nigeria most of whom are highly educated and have both the computer skills and access to the mobile phone which has the potential to bridge this digital divide by providing universal access and connectivity to all citizens, regardless of location or economic status. 
On what benefits older Nigerians derive from social relationships especially in terms of bonding social capital, that is, accessibility to rare resources and emotional and substantive support from SNS use, results show that overall, bonding social capital mien was relatively positive in respect of these variables. Results show the most likelihood of older adults accessing resources or substantive forms of capital exchanges typically associated with bonding social capital such as emotional support in terms of advice, helping to fight just causes, offering companionship in times of loneliness and the willingness to serve as job referees. Inversely however, older Nigerians do not seem to accept or trust friends or relations online well enough to feel comfortable talking to them about intimate personal problems or turn to them for financial assistance or expect them to share their last dollar. These results are predictive of very low levels of interpersonal trust as older adults appear least likely to access anything substantive from family members and friends helping them solve problems, including financial assistance, and sharing intimate personal problems. These results thus suggest that although older adults use social network sites primarily to maintain relationships with family members and close friends, mutual dependence on these ties does not necessarily support any tangible social outcomes for users. The value of maintaining such core social networks however has proved to be highly influential in decision-making and exposure to ideas, issues, and opinions, being an important source of information (Donath, 2007).

On the social utility of social networking sites for bridging social capital among older adults, results show a weak association between the use of SNSs and bridging social capital. A negative correlation between SNS use and substantive aspects of bridging social capital is inverse to older adults' strong desire among all older adults to connect with a wider circle of social relationships outside friends and relations and to be outward-looking towards broadening their social horizons or worldview. Older adults' strongest tendency may be to share feelings of interconnectedness to a larger community, curiosity about other places in the world, as well as the willingness to develop new ties and be part of and support community when interacting with strangers on social networking sites. But such linkages do not seem to translate to useful informational resources, a key component of bridging social capital. It is Older adults that may be using social networking sites to create and maintain larger, diffuse networks of relationships but it is doubtful if they are drawing potential bridging social capital resources in form of useful information, personal relationships, or the capacity to align with groups and broaden world-views (Donath \& Boyd, 2004; Resnick, 2001; Wellman, Haase, Witte, \& Hampton, 2001).

\section{Conclusion}

This study is an exploratory effort to investigate older adults' use of social network sites and establish the social capital implications of such social relationships and interactions. Overall, the results show the potential of the mobile phone to bridge this digital divide in terms of adequacy and equality of 
access, use and knowledge of ICT in Sub-Saharan Africa among all citizens, regardless of location or economic status. Older adults' communication interactions on SNS are seemingly constitutive of bonding social capital but these are not predictive of substantive forms of capital exchanges typically associated with bonding social capital such as helping others to solve problems including financial problems and discussing intimate personal problems.

Also, older adults may be outward-looking and inclined to initiating a wider circle of social relationships outside friends and relations but this tendency does not support bridging the social capital. Nonetheless, the internet and social media allow older Nigerians the opportunity to create and maintain larger, diffuse networks of relationships and also provide them with a range of benefits and opportunities to empower themselves in a variety of ways including facilitating supportive relationships among people that are predictive of social capital.

Given that this study focused primarily on a particular category of older adult Nigerians in one State, we cannot generalize our findings to all adult Nigerians. This limitation could be better addressed by a longitudinal study which would allow for alternate measures of participation on SNSs, social capital and other variables such as community or political engagement. An additional limitation of the study was the conceptualization of social capital only in terms of bonding and bridging social capital to the exclusion of other forms of social capital. Nevertheless, it is our hope that findings reported in this study contribute to the larger understanding of social capital on social network sites.

\section{References}

Appel, L., Dadlani, P., Dwyer, M., Hamptona, K., Kitzie, V., Matni, Z. A., Moore, P., \& Teodoro, R. (2014). Testing the validity of social capital measures in the study of information and communication technologies. Information, Communication \& Society, 17(4), 398-416.

Bargh, J. A., McKenna, K. Y., \& Fitzsimons, G. M. (2002). Can you see the real me? Activation and expression of the "true self" on the Internet. Journal of Social Issues, 58, 33-48.

Baugess, B. E. (2015). Examining Social Network Site Usage by Older Adults: A Phenomenological Approach (Unpublished doctoral dissertation). Graduate School of Computer and Information Sciences, Nova South-eastern University, USA.

Bell, C., Fausset, C., Farmer, S., Nguyen, J., Harley, L., Fain, W. B. (2013). Examining social media use among older adults. Proceedings of the $24^{\text {th }}$ ACM Conference on Hypertext and Social Media (pp. 158-163).

Burke, M., Marlow, C., \& Lento, T. (2010). Social network activity and social wellbeing. Proceedings of the $28^{\text {th }}$ international conference on human factors in computing systems, Atlanta, Georgia, USA, April 10-15.

Ciboh, R. (2015). Adult Users' Engagement and Utilisation of Social Networks Sites in Nigeria. Studies in Media and Communication, 3(2), 129-136.

Cotten, S., Ford, G., Ford, S., \& Hale, T. (2012). Internet Use and Depression among Older Adults. Computers in Human Behaviour, 28, 496-499. 
Donath, J. (2007). Signals in social supernets. Journal of Computer-Mediated Communication, 13(1), 231-251.

Donath, J., \& Boyd, D. (2004). Public displays of connection. BT Technology Journal, 22(4), 71-82.

Ellison, N., Steinfield, C., \& Lampe, C. (2007). The benefits of Facebook "friends": Exploring the relationship between college students' use of social networks and social capital. Journal of Computer Mediated Communication, 12(3), 1143-1168.

Ellison, N. B., Lampe, C., Steinfield, C. (2009). Social network sites and society: current trends and future possibilities. Interactions, 16(1), 6-9.

Ellison, N. B., Steinfield, C., Lampe, C. (2011). Connection strategies: Social capital implications of Facebook-enabled communication practices. New Media \& Society, 13(6), 873-892

eMarketer Report (2016, June 02). Worldwide Internet and Mobile Users: eMarketer's Estimates for 2016. Retrieved from goo.gl/H6Pumz.

Erickson, L. B. (2011). Social media, social capital, and seniors: the impact of Facebook on bonding and bridging social capital of individuals over 65. AMCIS Proceedings, 4-7 August, Detroit, USA. Retrieved from goo.gl/GQa1EC.

Ericsson. (2013). Bridging the digital divide: How mobile phones are playing a key role in connecting people in Sub-Saharan Africa. An Ericsson Consumer Insight Summary Report. Retrieved from goo.gl/ryTD1Y.

Ericsson (2015). Living longer: Wellness and the internet: The impact of the internet on consumer attitudes to health and fitness. An Ericsson Consumer Insight Summary Report. Retrieved from goo.gl/wH9tuY.

Farkas, P. A. (2010). Senior social platform - an application aimed to reduce the social and digital isolation of seniors. Proceedings of REAL CORP, 223, 12471252.

Furr, R. M. (2011). Scale construction and psychometrics for social and personality psychology. Los Angeles, CA: SAGE.

Gibson, L., Arnott, J., Moncur, W., Martin, C., Forbes, P., \& Bhachu, A. (2010). Designing social networking sites for older adults. Proceedings of the HCI10 Conference on People and Computers XXIV, Dundee, UK (pp. 186-194).

Granovetter, M. S. (1983). The strength of weak ties: A network theory revisited. Sociological Theory, 1, 201-233.

Gray, A. (2009). The social capital of older people. Ageing and Society, 29(1): 5-31.

Helliwell, J. F. K., \& Putnam, R. D. K. (2004). The social context of well-being. Philosophical Transactions of the Royal Society. Biological Sciences, 359, 14351446.

Hogeboom, D., McDermott, R., Perrin, K., Osman, H., \& Bell-Ellison, B. (2010). Internet Use and Social Networking Among Middle Aged and Older Adults. Educational Gerontology, 36(2), 93-111.

House, J. S., \& Kahn, R. L. (1985). Measures and concepts of social support. In S. Cohen \& S. L. Syme (Eds.), Social Support and Health (pp. 83-108). Orlando, FL: Academic Press.

House, J. S., Umberson, D., \& Landis, K. R. (1988). Structures and processes of social support. Annual Review of Sociology, 14, 293-318.

Internet World Stats. (2016, October 11). Internet usage and population statistics: Africa. Retrieved from goo.gl/YXExcL. [Accessed: 7 October 2016]

Johnston K., Chen, M-M., \& Hauman M. (2013). Use, Perception and Attitude of University Students Towards Facebook and Twitter. The Electronic Journal Information Systems Evaluation, 16(3), 201-211. 
Knobel, M., \& Lankshear, C. (2008). Digital Literacy and Participation in Online Social Networking Spaces (pp. 249-278). New York: Peter Lang.

Lampe, C., Ellison, N., \& Steinfield, C. (2006). A Face(book) in the crowd: Social sea rching vs. social browsing. Proceedings of CSCW2006. New York: ACM Press (pp. 167-170).

Lovett, G. (2011). Over 50's drive Facebook growth. Marketing Week. Retrieved from goo.gl/gTcAyg.

Lin, J-H., Peng, W., Kim, M., Kim, S. Y., \& LaRose, R. (2011). Social networking and adjustments among international students. New Media \& Society, 14(3), 421440.

Nef, T., Ganea, R. L., Müri, R. M., \& Mosimann, U. P. (2013). Social networking sites and older users - a systematic review. International Psychogeriatrics, 25(7), $1-13$.

Norris, P. (2002). The bridging and bonding role of online communities. Harvard International Journal of Press/Politics, 7(3), 3-13.

Papacharissi, Z., \& Mendelson, A. (2008). Toward a new(er) sociability: Uses, gratifications, and social capital on Facebook. Paper presented at the Internet Research Conference, October 2008, Copenhagen, Denmark.

Pempek, T. A., Yermolayeva, Y. A., \& Calvert, S. L. (2009). College students' social networking experiences on Facebook. Journal of Applied Developmental Psychology, 30(3), 227-238.

Phulari, S. S., Khamitkar, S., Deshmukh, N., Bhalchandra, P., Lokhande, S., \& Shinde, A. R. (2010). Understanding formulation of social capital in online social network sites (SNS). International Journal of Computer Science Issues, 7(1), 92-96.

Pfeil, U. (2007). Online social support for older people. SIGACCESS Accessibility \&. Computing, 88, 3-8.

Pfeil, U., \& Zaphiris, P. (2007). Patterns of empathy in online communication. Proceedings of CHI 2007 - The ACM conference on human factors in computing systems CHI'07, 28 April-03 May, 2007, San Jose, CA; New York, NY: ACM Press (pp. 919-928).

Poortinga W. (2012). Community resilience and health: the role of bonding, bridging, and linking aspects of social capital. Health \& Place, 18(2), 286-295.

Putnam, R. (2000). Bowling alone: The collapse and revival of American community. New York, NY: Simon \& Schuster.

Rainie, L., \& Wellman, B. (2012). Networked: The new social operating system. Cambridge, MA: MIT Press.

Resnick, P. (2001). Beyond bowling together: Sociotechnical capital. In J. Carroll (eds.), HCI in the New Millennium (pp. 247-272). Boston, MA: AddisonWesley.

Saunders, M. N. K., Lewis, P., \& Thornhill, A. (2012). Research methods for business students (6th ed.). Harlow, England: Pearson Education.

Seal-World (2014, January 24). Amazing Social Media Statistics in Nigeria Part 1. Retrieved from goo.gl/rnPV2m.

Seeman, T. E., Lusignolo, T. M., Albert, M., Berkman, L. (2001). Social relationships, social support, and patterns of cognitive aging in healthy, high-functioning older adults: Macarthur studies of successful aging. Health Psychology, 20, 243-255.

Shklovski, I., Kraut, R., Rainie, L. (2004). The Internet and social participation: contrasting cross-sectional and longitudinal analyses. Journal of ComputerMediated Communication, 10(1).

Smith, A. (2014). Older Adults and Technology Use: Adoption is increasing,but many seniors remain isolated from digital life. Retrieved from goo.gl/n0738Q. 
Steinfield, C., Ellison, N. B., \& Lampe, C. (2008) Social capital, self-esteem, and use of online social network sites: a longitudinal analysis. Journal of Applied Developmental Psychology, 29(6): 415-474.

Sundar, S., Oeldorf-Hirsch, A., Nussbaum, J., \& Behr, R. (2011). Retirees on Facebook: can online social networking enhance their health and wellness? Proceedings of $\mathrm{CHI}$ Extended Abstracts. Vancouver, BC, Canada (pp. 2287-2292).

Szreter, S., \& Woolcock M. (2004). Health by association? Social capital, social theory, and the political economy of public health. International Journal of Epidemiology, 33(4): 650-667.

Wagner, N., Hassanein, K., \& Head, M. (2010). Computer use by olderadults: A multi-disciplinary review. Computer in Human Behaviour, 26, 870-882.

Wellman, B., Haase, A. Q., Witte, J., \& Hampton, K. (2001). Does the Internet Increase, Decrease, or Supplement Social Capital? Social Networks, Participation, and Community Commitment. American Behavioural Scientist, 45(3), 436-455.

Wellman, B., \& Hampton, K. (1999). Living networked on and offline. Contemporary Sociology, 28(6), 648-654.

Williams, D. (2006). On and off the net: Scales for social capital in an online era. Journal of Computer-Mediated Communication, 11, 593-628.

Woolcock, M. (2001). The place of social capital in Understanding Social and Economic Outcomes. ISUMA Canadian Journal of Policy Research, 2(1), 11-17.

Woolcock, M., \& Sweetser, A. T. (2002). Bright ideas: social capital - the bonds that connect. ADB Review, 34(2), 1-26.

World Bank. (1997). World development report 1997: The state in a changing world. New York: Oxford University Press.

WHO - World Health Organisation. (2014). World Health Statistics 2014: Large gains in life expectancy. Retrieved from goo.gl/ubzjBZ.

Wright, K. B. (2000). The communication of social support within an on-line community for older adults: A qualitative analysis of the SeniorNet community. Qualitative Research Reports in Communication, 1(2), 33-43.

Xie, B. (2007). Older Chinese, the internet, and well-being. Care Management Journals: Journal of Long Term Home Health Care, 8(1), 33-38.

Zhang, F., \& Kaufman, D. (2015). Social and emotional impacts of Internet use on older adults. European Scientific Journal, 11(17), 1-15. 
